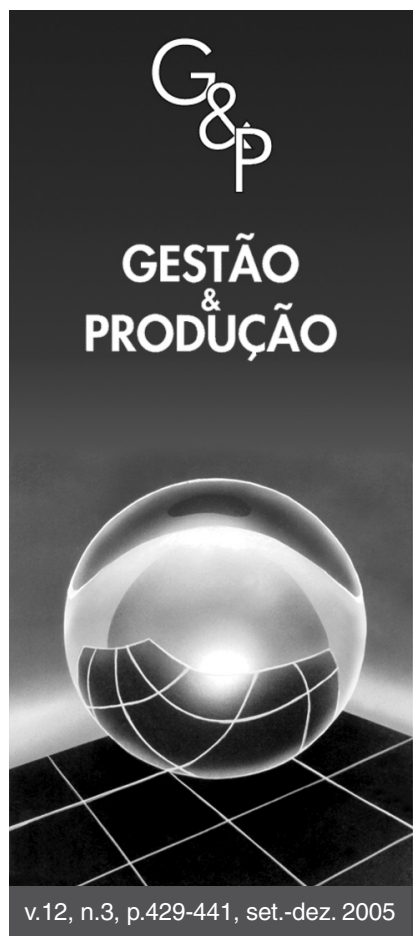

\title{
ESTRATÉGIA E ESTRUTURA: EM BUSCA DO ALINHAMENTO ORGANIZACIONAL EM UM CLUBE SOCIAL ESPORTIVO
}

\author{
Augusto de Toledo Cruz Junior \\ Marly Monteiro de Carvalho \\ Fernando José Barbin Laurindo \\ Departamento de Engenharia de Produção, \\ Escola Politécnica da Universidade de São Paulo, \\ Av. Prof. Almeida Prado, 128, trav. 2, CEP 05508-900, São Paulo, SP, \\ e-mail: seneng@uol.com.br, marlymc@usp.br, fjblau@usp.br
}

Resumo

A literatura descreve tipologias de formas organizações, que podem ser divididas em organização baseada em trabalho e organização baseada em conhecimento. A forma de representação mais utilizada é o organograma. Contudo, esta forma de representação não consegue ilustrar adequadamente a dinâmica de funcionamento da organização, sobretudo em organizações em que o conhecimento e a experiência são os ativos-chave. Com o objetivo de investigar o processo de alinhamento entre estratégia e estrutura, a abordagem metodológica adotada foi a pesquisa-ação. A pesquisa foi realizada ao longo de 6 meses, no período dos anos 2003 e 2004, em um clube situado na cidade de São Paulo. Participaram da pesquisa um grupo de 12 gerentes, 10 supervisores, 9 coordenadores e 5 dos principais diretores. Este artigo mostra como um clube de atividades sociais, culturais e esportivas projetou sua estrutura organizacional alinhada à formação de competências e às suas dinâmicas de funcionamento, para operar com características de uma organização baseada em conhecimento. A nova forma de representação da estrutura organizacional, denominada organigraph, ajudou o clube a explicitar a estratégia emergente, para operar em um mercado competitivo turbulento e implementá-la como regra simples a ser seguida por todos. Além disto, é apresentado um modelo de avaliação do desempenho derivado de um organigraph.

Palavras-chave: estratégia em serviços, formação de competências, estruturas organizacionais, organigraph.

\section{Introdução}

Usualmente, os clubes não são associados a grandes prestadores de serviços. No entanto, são organizações representativas na sociedade, pois empregam um grande contingente de pessoas trabalhando em jornadas diárias extensas, incluindo domingos e feriados, e em quase todos os dias do ano. Principalmente os clubes situados nos grandes centros urbanos vivem em um ambiente turbulento e competitivo cujos concorrentes nem sempre são outros clubes, tanto que, muitas vezes, se associam em entidades para trocar experiências. Na prática, tornam-se os concorrentes mais próximos as academias, centros de convivência e lazer, bares, restaurantes, cinemas, bingos, snooker, teatro, bibliotecas, escolas, centros de tratamento estético, local para eventos e convenções, parques, etc., que sejam próximos da residência ou local de trabalho do associado e seus dependentes. Além disso, pode haver alternativas dentro do próprio condomínio em que o associado habita, na organização em que trabalha, ou na escola que freqüenta. Até shopping centers, ou mesmo estradas que dão acesso rápido ao litoral ou interior, também podem se tornar competidores mais capacitados do que os clubes.

Este artigo visa discutir o impacto da estrutura na formação de competências e implementação da estratégia e 
está estruturado em cinco seções. A seção 2 apresenta o quadro conceitual utilizado para estratégia e estrutura. A seção 3 apresenta a abordagem metodológica utilizada. A seção 4, a pesquisa de campo feita em um clube, detalhando as estratégias desenvolvidas para sobreviver no ambiente competitivo e o projeto da estrutura organizacional mais adequada para conduzir estas estratégias. Finalmente, a seção 5 apresenta as conclusões da pesquisa.

\section{Estratégia e estrutura: quadro conceitual}

Conforme o levantamento realizado por Carvalho e Laurindo (2003, p. 160), "vários autores enfatizam a necessidade de mudança da estratégia perante as mudanças cada vez mais rápidas no ambiente competitivo". Dentre esses autores destaca-se o trabalho de Eisenhardt e Sull (2001), que identificaram uma nova forma de conduzir o processo estratégico em ambientes turbulentos, a qual foi denominada de estratégia como regras simples. A Tabela 1 apresenta as principais características dessa estratégia.

Eisenhardt e Sull (2001) alertam que é impossível estabelecer exatamente o que são as regras simples, mas é possível afirmar o que elas não devem ser:

a) amplas: os administradores freqüentemente confundem os princípios que guiam uma organização com regras simples;

b) vagas: algumas regras cobrem um único processo, mas são vagas demais para serem um guia; e

c) sem sentido: organizações cujas regras simples mantiveram-se implícitas podem concluir após examiná-las que estas regras mais destroem do que criam valor.

Essa forma de conduzir o processo estratégico, adequado para mercados turbulentos, pode ser dividida por alguns tipos de regras, conforme apresentado na Tabela 2.

Tabela 1. Estratégia como regras simples. Fonte: adaptado de Eisenhardt e Sull (2001, p. 109).

\begin{tabular}{ll}
\hline Lógica estratégica & Tática de perseguir oportunidades \\
\hline Passos estratégicos & Arriscar dentro da confusão \\
& $\begin{array}{l}\text { Manter em movimento } \\
\text { Agarrar oportunidades }\end{array}$ \\
& $\begin{array}{l}\text { Finalizar forte } \\
\text { Questão estratégica }\end{array}$ \\
Como deveríamos proceder? \\
Fonte de lucro & $\begin{array}{l}\text { Processos-chave e regras simples exclu- } \\
\text { sivas }\end{array}$ \\
Funciona melhor em & Mudança rápida, mercados incertos \\
Duração do lucro & $\begin{array}{l}\text { Imprevisível } \\
\text { Risco }\end{array}$ \\
& $\begin{array}{l}\text { Oportunidades promissoras serão exe- } \\
\text { cutadas em termos de tentativas pelos } \\
\text { administradores }\end{array}$ \\
Atuação do objetivo & Crescimento \\
\hline
\end{tabular}

Com a utilização das regras simples, fica mais fácil incorporar as estratégias emergentes que, segundo Mintzberg e Waters (1985), resultam das respostas no trabalho diário às ameaças e oportunidades, daqueles gerentes que têm a tarefa de implementar a estratégia da organização. Desta forma, diminui-se a lacuna (gap) entre estratégias intencionais e as emergentes, evitando a dissociação da estratégia e da ação.

\subsection{Tipologia das organizações e a importância da competência}

A extensa literatura descreve tipologias de formas organizações, que podem ser divididas em organização baseada em trabalho e organização baseada em conhecimento (Lawler, 1994 apud Lindgren et al., 2003). Uma organização baseada no trabalho pode ser descrita como um conjunto de máquinas que coordena bem um repertório fixo de rotinas, em que o quadro que se vê é a ordem, a previsibilidade e a hierarquia (Lindgren et al., 2003).

Drucker $(1988,1993)$ apud Lindgren et al. (2003, p. 21) "cunhou a frase "trabalho de conhecimento" como aquele que desafia a rotina e requer o uso da criatividade na sua produção, cuja importância é crescente na sociedade emergente pós-industrial (Blackler, 1995 apud Lindgren et al., 2003). Conforme Lindgren et al. (2003), esse conceito é estendido para as organizações que convivem em um ambiente de mudanças, sob exigências inesperadas e um aprendizado contínuo. Neste tipo de organização, os autores argumentam que há uma necessidade constante de inovação, que requer o uso de sistemas de competências desenvolvidas sobre os próprios interesses dos indivíduos no trabalho e que possam ser utilizados pela organização baseada em conhecimento.

Lindgren et al. (2003) ressaltam que, embora o termo habilidade, algumas vezes, seja tratado de maneira semelhante à competência, a diferença entre os termos é que

Tabela 2. Tipos de regras simples. Fonte: adaptado de Eisenhardt e Sull (2001, p. 111).

\begin{tabular}{ll}
\hline \multicolumn{1}{c}{ Tipo } & \multicolumn{1}{c}{ Proposta } \\
\hline Regras de how-to & $\begin{array}{l}\text { Características-chave de como um } \\
\text { processo é executado - "O que faz um } \\
\text { projeto ser único?" }\end{array}$ \\
Regras de fronteira & $\begin{array}{l}\text { Focam os gerentes sobre quais oportuni- } \\
\text { dades podem ser seguidas e quais estão } \\
\text { fora. }\end{array}$ \\
Regras de prioridade & $\begin{array}{l}\text { Ajudam os gerentes a classificar as } \\
\text { oportunidades aceitas. }\end{array}$ \\
Regras de tempo & $\begin{array}{l}\text { Sincronizam gerentes com o passo das } \\
\text { oportunidades emergentes e outras } \\
\text { partes da organização. } \\
\text { Ajudam os gerentes a decidir quando } \\
\text { Regras de saída }\end{array}$ \\
\hline
\end{tabular}


a habilidade pode ser entendida no aspecto individual, enquanto a competência é discutida no nível organizacional. O significado da palavra competência, oriunda do latim competere, pode ser interpretado como conjunto de esforços (Rabechini Jr., e Carvalho, 2003). Assim sendo, "a capacidade de conhecer suas próprias potencialidades e de como desenvolvê-las de maneira consistente pode ser decisiva para um posicionamento de sucesso no cenário competitivo" (Carvalho e Laurindo, 2003, p. 63).

Apesar da organização baseada em conhecimento se contrapor à rigidez da organização baseada no trabalho, não significa que não possam conviver e que sejam mutuamente excludentes. "Normalmente, ambas as formas podem ser encontradas em áreas diferentes, departamentos, ou níveis dentro da mesma organização" (Nonaka, 1994 apud Lindgren et al., 2003, p. 21).

\subsection{Representação de uma organização}

Quando se quer representar uma organização, geralmente se faz uso de organogramas, os quais, na prática, se tornaram irrelevantes no mundo atual (Mintzberg e Heyden, 1999), pois mostram, principalmente, a relação de poder, não conseguindo representar a dinâmica de funcionamento da organização. Em função disso, Mintzberg e Heyden (1999) experimentaram novas formas de desenhar e ver as organizações, resultando numa proposta que eles denominaram organigraph, o que pode ser desconcertante no primeiro instante para quem está habituado com a elaboração de organogramas, pois não há regras rígidas, nem um organigraph que possa ser considerado certo, como ocorre com os organogramas. Segundo Mintzberg e Heyden (1999, p. 90, grifo nosso), "para desenhar um organigraph você deve aceitar o fato de que ele mostra mais relacionamentos e processos do que nomes e títulos" dos organogramas. Um organigraph requer gerentes para criar alguma coisa que envolva imaginação e uma mente aberta, deixando o lado imagem de um organograma para um lado mapa que dá uma visão do território da organização (Mintzberg e Heyden, 1999).

$\mathrm{O}$ termo organigraph mistura as palavras organograma e gráfico e não elimina os organogramas e seus componentes, como caixas contendo a indicação do poder e setas com o relacionamento entre as caixas, mas introduz novos componentes que procuram refletir as várias maneiras como as pessoas se organizam atualmente no trabalho. Estes novos componentes são denominados ponto central ( $h u b$ em inglês) e rede (web em inglês), conforme descreve a Figura 1.

Para estes autores, os novos componentes - ponto central $(h u b)$ e rede $(w e b)$ - podem ser definidos da seguinte forma:

Um hub serve como um centro de coordenação. É qualquer ponto físico ou conceitual para o qual pessoas, coisas e informações se movem.

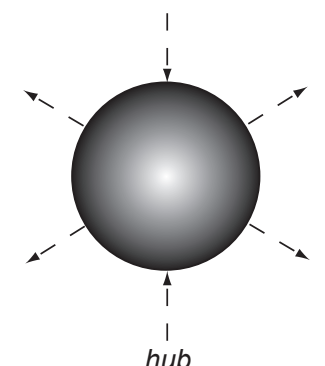

Figura 1. Componentes do organigraph. Fonte: Mintzberg e Heyden (1999).

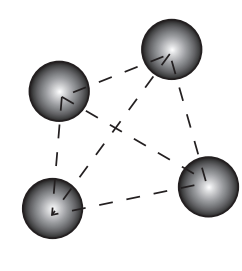

web
Webs são conexões sem um centro: elas permitem comunicação aberta e movimentação contínua de pessoas e idéias (Mintzberg e Heyden, 1999, p. 5).

O ponto central pode ser um prédio, uma máquina. Um gerente pode ser um ponto central. Além disso, uma competência essencial (core competence, conforme Prahalad e Hamel (1990)) pode ser um ponto central, como por exemplo, a ótica na Canon ou a aderência na 3M (Mintzberg e Heyden, 1999). Inserir esse componente no organigraph da organização indica que todas as atividades estão relacionadas a ele (Mintzberg e Heyden, 1999).

O ponto central $(h u b)$, que não tem uma representação gráfica específica, retrata o movimento para e de em um ponto de conexão, mas, muitas vezes, conexões são mais complicadas do que isto. Entra, então, a rede, a qual também não tem uma representação gráfica específica.

Nós somos freqüentemente lembrados de que vivemos em rede e os diferentes nós podem ser pessoas, times, computadores ou qualquer coisa mais, conectados em todos os tipos de possibilidades.

De acordo com Mintzberg e Heyden (1999), enquanto em um ponto central, os gerentes atraem e coordenam as atividades, na rede, os gerentes ligam e dão energia. Além de simplesmente introduzir novos componentes, Mintzberg e Heyden (1999) sugerem que o novo vocabulário dos organigraphs pode expandir, como vemos, as organizações, pode mesmo expandir nosso pensamento sobre a direção estratégica.

Nonaka e Takeuchi (1997) também idealizaram uma estrutura que permite identificar a base de conhecimento, a qual denominaram de estrutura hipertexto. Esta estrutura combina três contextos distintos - sistema de negócio, equipes de projeto e base de conhecimento. $\mathrm{O}$ contexto de sistema de negócio evidencia a estrutura funcional tradicional, voltada para as atividades de rotina. As equipes de projeto são estruturas temporárias dedicadas exclusivamente a um projeto, até a sua conclusão, as pessoas que compõem estas equipes são oriundas do contexto do sistema de negócio. Finalmente, o contexto da base de 
conhecimento é uma representação simbólica, que não existe como estrutura organizacional, mas evidencia a criação do conhecimento.

\section{Abordagem metodológica}

As principais questões discutidas neste trabalho são: identificar qual é o processo de formulação de estratégias intencionais e emergentes; identificar qual é o tipo de estrutura mais adequado em face das estratégias; identificar as dinâmicas de funcionamento e os processos que permitam a implementação da estratégia.

A estratégia de pesquisa adotada foi a pesquisa-ação, pois se pretendia estudar as questões citadas anteriormente, em tempo real, com a co-participação interativa dos pesquisadores, visando ao propósito de desenvolver um entendimento holístico da situação em estudo (Coughlan e Coghlan, 2002).

A organização selecionada para o estudo foi um clube de grande porte situado na cidade de São Paulo, freqüentado por empresários, profissionais liberais e funcionários de organizações, o qual contempla seus associados com todas as atividades que um clube tradicional possui.

Como instrumento da pesquisa foram realizadas entrevistas, workshops e análise dos documentos e dos sistemas de informação. O grupo de trabalho no clube era constituído de todos os 12 gerentes, além de 10 supervisores e 9 coordenadores ligados aos gerentes. No que concerne aos diretores do clube, foram consultados 20 , dos quais 5 se envolveram mais ativamente no processo de redefinição da estrutura. Ressalta-se que existem mais diretores do que gerentes. Enquanto os gerentes são funcionários não associados que possuem a visão de fornecedor, os diretores são associados não remunerados para a função, que, além de serem consumidores, também representam os interesses dos demais associados na gestão do clube. A pesquisa foi realizada ao longo de 6 meses com três ciclos de detalhamento. O primeiro ciclo foi de análise das estratégias, o segundo ciclo de análise da estrutura e o terceiro ciclo de análise dos processos e indicadores.

\section{Resultado da pesquisa}

O Clube oferece aos seus associados principalmente atividades esportivas, sociais e culturais, além da disponibilidade de alimentação em ambiente seguro, visando que o associado possa permanecer o maior tempo possível dentro do Clube, com comodidade e conforto. Possui cerca de 5.000 títulos ativos, com cerca de 4 dependentes para cada título, entre descendentes e ascendentes, o que resulta em cerca de 20.000 associados envolvidos nas suas atividades. Conta com cerca de 400 funcionários permanentes e uma grande quantidade de concessionários, como, por exemplo, bares, cabeleireiros, barbeiros, etc., e contratados que trabalham no interior do Clube, ora como empregados dos concessionários, ora como temporários para atividades de segurança, instrutores especializados, limpeza, etc.

A estrutura do Clube, sintetizada no organograma da Figura 2, é gerida por uma Diretoria Executiva, da qual fazem parte o presidente e alguns dos diretores, nomeados por um conselho que é eleito pelos associados. Os conselheiros, a presidência e os diretores não são remunerados e não fazem parte individualmente do organograma (somente a Diretoria Executiva). Abaixo da Diretoria Executiva se encontram os Departamentos com profissionais remunerados comandados por gerentes subordinados informalmente aos diretores das suas áreas e formalmente à Diretoria Executiva.

Para os associados, estão claros os produtos das áreas que utilizam diretamente, ou seja, dos Esportes, do Sociocultural, dos Alimentos e Bebidas e da Administração, pois a linha de visibilidade (Kingman-Brundage, 1995) do associado alcança todos os executores e controladores dos processos que resultam nestes produtos. Os produtos das demais áreas agrupadas sob a denominação de Suporte, visam atender principalmente às necessidades das áreas anteriormente citadas. Devido à própria natureza do serviço prestado ser abaixo da linha de visibilidade do associado (Kingman-Brundage, 1995), os serviços prestados pelo Suporte nem sempre são percebidos pelos associados.

A cada 2 anos a presidência pode sofrer alteração, ou ser confirmada para um período de mais 2 anos. A nomeação dos diretores das áreas ocorre principalmente em função das diretrizes da Diretoria Executiva. Esse tipo de procedimento, bem como o próprio funcionamento do Clube, assemelha-se, em parte, ao modo de agir de uma organização governamental.

\subsection{Identificação das competências}

O sistema de gestão de operações do Clube era convencional, muito semelhante ao que praticam outros clubes. No entanto, por influência de diretores que também são empresários, nos últimos anos, decidiu-se implantar um sistema da qualidade certificado pela norma NBR ISO 9002:1994 (ABNT, 1994), que é uma das normas da série ISO 9000. Iniciou-se pelos setores (ver Figura 2) de Formação Esportiva do Departamento de Esportes e Central de Atendimento do Departamento de Administração.

Em seguida, estendeu-se o processo de certificação para o restante do Clube, atualmente, segundo a norma NBR ISO 9001:2000 (ABNT, 2000).

Com base no terreno fértil de discussão e redefinição dos processos, motivadas pela implementação da norma de Sistema de Gestão da Qualidade, foi possível identificar as competências do Clube.

O Clube possui competências comuns em vários dos setores cujos produtos se encontram envolvidos com 


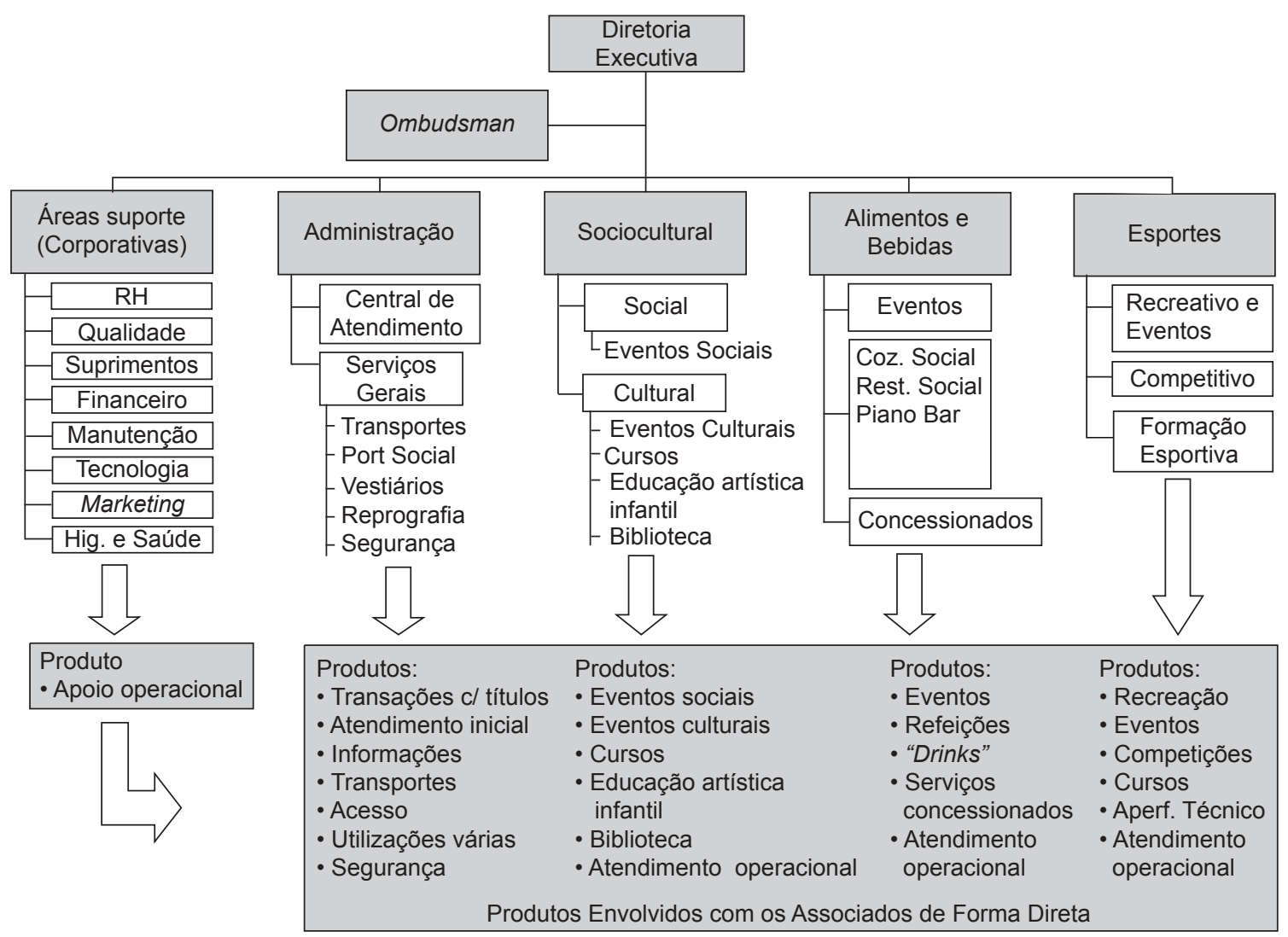

Figura 2. Estrutura do Clube e os produtos resultantes. Fonte: documentação da organização pesquisada.

os associados de forma direta. Além disso, percebeu-se que essas competências justificavam boa parte da vantagem competitiva ante seus competidores. Em função desse aprendizado, verificou-se, então, que seria necessário redefinir a estrutura do Clube para potencializar as competências e alinhar os processos. A estrutura, conforme Figura 2, não se mostrava adequada, sendo, então, apresentada para o grupo a estrutura organigraph como uma alternativa de representação. A Figura 3 apresenta o organigraph elaborado para representar as competências identificadas que se encontram nos processos de Atendimento, da Formação \& Performance e do Lazer \& Entretenimento.

A essência da competência Atendimento é conseguir criar produtos que proporcionem uma atmosfera de atendimento personalizada para o associado, fazendo-o sentir-se, não como um consumidor, mas como um participante da organização do Clube. Contribuem para os processos de Atendimento os Departamentos de Administração, Sociocultural, de Alimentos e Bebidas e de Esportes.

A essência da competência Formação \& Performance consiste na elaboração de programas de cursos e treinamentos que se atualizam continuamente, mesmo em modalidades tradicionais das áreas de Esportes e Sociocultural, contando com cerca de 5000 alunos matriculados. Em geral, esses programas são revistos livremente

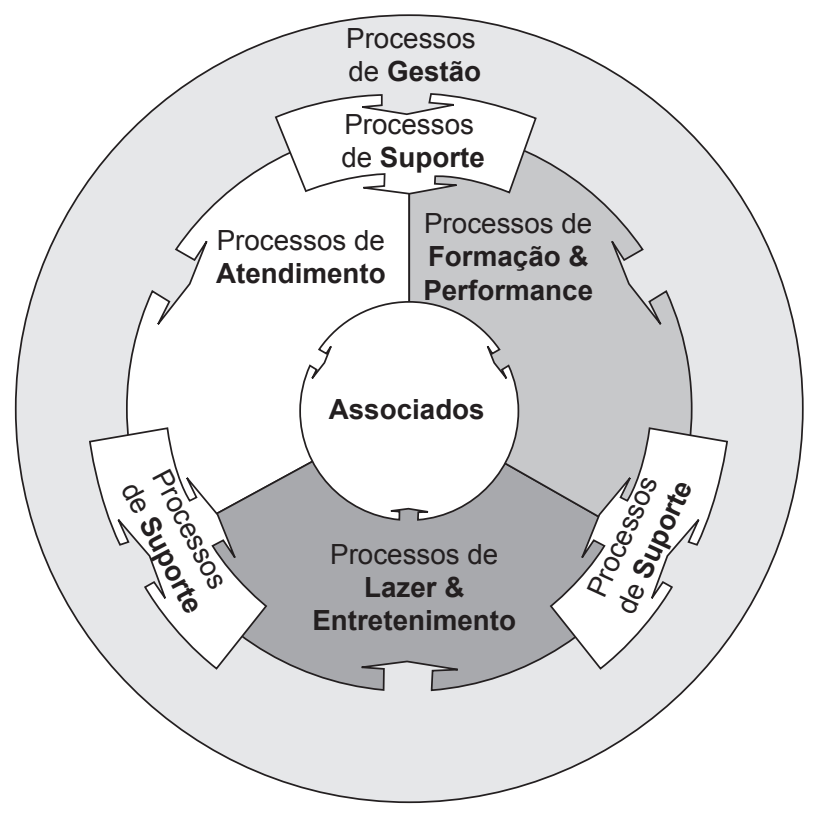

Figura 3. Organigraph do Clube. Fonte: documentação da organização pesquisada.

por grupos de professores e treinadores a cada novo período de matrículas, e submetidos à aprovação dos demais grupos de professores e treinadores e coordenadores. 
Além disso, nesses programas são integrados inúmeros eventos de disputa no próprio Clube, ou fora dele, que proporcionam um aprendizado da própria situação em relação aos demais participantes dos eventos. Contribuem para os processos de Formação \& Performance setores dos Departamentos de Esporte e Sociocultural.

A competência Lazer \& Entretenimento cria produtos conjuntos que acabam levando o associado a se envolver com os vários setores do Clube, atingindo-o de maneira ativa, ou seja, cobrando a sua participação e não simplesmente a disponibilizando de maneira passiva. Uma das características é que o associado está sendo acionado diariamente para o consumo desses produtos, ou seja, mantendo-o a maior parte do tempo na convivência do Clube. Contribuem para os processos de Lazer \& Entretenimento a Administração, Alimentos e Bebidas, e setores do Sociocultural e do Esporte.

\subsection{Funcionalidade do organigraph do clube}

Os processos representados no organigraph explicitam a cadeia de valor (interna) do Clube (ver Figura 3) como uma rede (web), que permite uma comunicação aberta e um contínuo movimento de pessoas e idéias, tendo no centro os consumidores dos serviços, que são os associados. Todos os processos são envolvidos pela Gestão e apoiados pelo Suporte, que é a parte da organização baseada no trabalho (ver 2.1). Entre eles, em contato permanente com os associados, se encontram as competências representadas como pontos centrais (hubs), que são partes da organização baseadas no conhecimento, e agem como coordenadores que interpretam as necessidades dos associados e realizam os produtos (simbolizados pelas setas da Figura 3) que são consumidos pelos associados como resultado das transformações das entradas em saídas (ver Tabela 4) dentro da rede (web) do organigraph. Os associados iniciam o ciclo de transformações como fornecedores da Gestão, e também finalizam o ciclo como clientes dos processos em que se encontram identificadas as competências, como pode ser visto em destaque no relacionamento fornecedor/cliente dos processos do organigraph do Clube, conforme apresentado na Tabela 3.

\subsection{Estratégia como regra simples}

Conforme apresentado anteriormente, foi necessário redefinir a estrutura do Clube, para potencializar as competências e alinhar os processos, cuja associação pode ser visualizada no organigraph. Além disto, a flexibilidade e a rapidez de resposta às demandas dos clientes gerou a regra simples da ação integrada dos setores envolvidos nessas competências para manter o associado no Clube.

Como sugere Kingman-Brundage (1995), a ação integrada dos setores causa no associado a experiência de um serviço sem costura (seamless em inglês, significando que o associado não percebe separações entre os setores). Essa estratégia propicia a disponibilidade de inúmeras atividades esportivas, culturais e sociais, na maioria das modalidades que os concorrentes praticam. A ação integrada permite que as atividades também não compitam entre si, mas se completem, sendo restritas mais pela impossibilidade de expandir os horários e pela indisponibilidade de locais para executá-las.

A regra simples de ação integrada como estratégia do Clube, estabelecida principalmente para os processos em que são desenvolvidas as competências estratégicas, resulta em que o associado ou parte da sua família esteja sempre em alguma atividade do Clube. É comum que todos os elementos de uma família acabem passando pelo Clube em um mesmo dia, quando não estão realizando atividades em paralelo. Como é permitido o acesso de familiares ascendentes, e também babás, motoristas, enfermeiros e demais empregados dos associados voltados para cuidar da sua família, as dificuldades naturais para o comparecimento dos dependentes desaparecem.

Essa situação acabou criando vantagens competitivas, pois em apenas um local:

a) encontram-se todas as facilidades para a realização de atividades que, fora do Clube, exigiriam logística e grandes deslocamentos para serem realizadas;

b) o custo para realizar as atividades de maneira integrada é inferior à contratação individual das mesmas atividades; e

c) têm-se segurança e alimentação garantidas em todo o período de funcionamento, permitindo a permanência nesse período.

A regra simples adotada acaba sendo classificada em mais de um tipo da Tabela 2. Pode ser do tipo fronteira, pois foca os gerentes sobre as oportunidades que devem ser aproveitadas para manter o associado no Clube, desconsiderando as demais. Também pode ser do tipo prioridade, pois ajuda os gerentes a classificarem as oportunidades por um só foco. Finalmente, pode ser também a regra de tempo, pois sincroniza os gerentes das áreas simultaneamente para as mesmas oportunidades.

\subsection{0 julgamento da estratégia adotada}

O Sistema de Gestão da Qualidade é projetado para atender a requisitos (necessidades ou expectativas expressas geralmente de forma implícita ou obrigatória) determinados. Como o Sistema implementado exige constante medição e monitoramento da satisfação dos associados e a melhoria contínua de sistema, são utilizados indicadores que medem periodicamente a eficiência dos processos, mapeados no organigraph. Desta forma, o sistema de indicadores do Sistema de Gestão da Qualidade seria então utilizado como ferramental para difusão, manutenção e mensuração da estratégia. 
Tabela 3. Relacionamento fornecedor/cliente dos processos do organigraph do clube. Fonte: documentação da organização pesquisada.

\begin{tabular}{|c|c|c|c|c|c|c|c|}
\hline Fornecedores & $\rightarrow$ & Entradas & $\rightarrow$ & Processos & $\rightarrow$ & Saídas & $\rightarrow$ Clientes \\
\hline Associados & $\rightarrow$ & $\begin{array}{l}\text { Situação e resultados dos } \\
\text { objetivos da qualidade }\end{array}$ & $\rightarrow$ & Gestão & $\rightarrow$ & $\begin{array}{l}\text { Informações para } \\
\text { planejamento }\end{array}$ & $\rightarrow$ Áreas Suporte \\
\hline Áreas Suporte & $\rightarrow$ & Oportunidades & $\rightarrow$ & & $\rightarrow$ & Planos de melhoria & $\rightarrow$ Administração \\
\hline Administração & $\rightarrow$ & Resultados de auditorias & $\rightarrow$ & & $\rightarrow$ & Recursos & $\rightarrow$ Sociocultural \\
\hline Sociocultural & $\rightarrow$ & $\begin{array}{l}\text { Realimentação de } \\
\text { associados }\end{array}$ & $\rightarrow$ & & $\rightarrow$ & $\begin{array}{l}\text { Avaliações de } \\
\text { adequações }\end{array}$ & $\rightarrow$ Alimentos \& Bebidas \\
\hline Alimentos \& Bebidas & $\rightarrow$ & $\begin{array}{l}\text { Desempenho de processos, } \\
\text { produtos e serviços }\end{array}$ & $\rightarrow$ & & $\rightarrow$ & Planos de prevenção & $\rightarrow$ Esportes \\
\hline \multirow[t]{3}{*}{ Esportes } & $\rightarrow$ & $\begin{array}{l}\text { Situação dos } \\
\text { planos de ação }\end{array}$ & $\rightarrow$ & & $\rightarrow$ & Estratégias & \\
\hline & & Pendências & $\rightarrow$ & & $\rightarrow$ & Políticas & \\
\hline & & Alterações no sistema & $\rightarrow$ & & & & \\
\hline Alta Direção & $\rightarrow$ & $\begin{array}{l}\text { Planos, políticas e } \\
\text { estratégias }\end{array}$ & $\rightarrow$ & Suporte & $\rightarrow$ & $\begin{array}{l}\text { Contratações, transferên- } \\
\text { cias e treinamentos }\end{array}$ & $\rightarrow$ Administração \\
\hline Rec. Humanos & $\rightarrow$ & $\begin{array}{l}\text { Necessidades de } \\
\text { competência }\end{array}$ & $\rightarrow$ & & $\rightarrow$ & Controle do SQ & $\rightarrow$ Sociocultural \\
\hline Qualidade & $\rightarrow$ & Necessidades para o SQ & $\rightarrow$ & & $\rightarrow$ & Recursos materiais & $\rightarrow$ Alimentos \& Bebidas \\
\hline Suprimentos & $\rightarrow$ & Necessidades de compras & $\rightarrow$ & & $\rightarrow$ & Recurso financeiro & $\rightarrow$ Esportes \\
\hline Financeiro & $\rightarrow$ & Recursos financeiros & $\rightarrow$ & & $\rightarrow$ & $\begin{array}{l}\text { Infra-estrutura e } \\
\text { ambiente de trabalho }\end{array}$ & \\
\hline Manutenção & $\rightarrow$ & $\begin{array}{l}\text { Necessidades de } \\
\text { infra-estrutura geral }\end{array}$ & $\rightarrow$ & & $\rightarrow$ & $\begin{array}{l}\text { Revista, Banners, } \\
\text { Folders, Painéis, etc. }\end{array}$ & \\
\hline Tecnologia & $\rightarrow$ & $\begin{array}{l}\text { Comunicação } \\
\text { com o associado }\end{array}$ & $\rightarrow$ & & $\rightarrow$ & Exames, socorros, etc. & \\
\hline Marketing & $\rightarrow$ & Atendimento médico & $\rightarrow$ & & & & \\
\hline Alta Direção & $\rightarrow$ & Planos, políticas e estratégias & $\rightarrow$ & Atendimento & $\rightarrow$ & Transações com títulos & $\rightarrow$ Associados \\
\hline Rec. Humanos & $\rightarrow$ & Dúvidas & $\rightarrow$ & & $\rightarrow$ & Informações gerais & \\
\hline Qualidade & $\rightarrow$ & Sugestões & $\rightarrow$ & & $\rightarrow$ & Informações específicas & \\
\hline Suprimentos & $\rightarrow$ & Reclamações & $\rightarrow$ & & $\rightarrow$ & Transporte & \\
\hline Financeiro & $\rightarrow$ & Esclarecimentos & $\rightarrow$ & & $\rightarrow$ & Acesso & \\
\hline Manutenção & $\rightarrow$ & & & & $\rightarrow$ & Segurança & \\
\hline Tecnologia & $\rightarrow$ & & & & $\rightarrow$ & $\begin{array}{l}\text { Atendimento } \\
\text { operacional }\end{array}$ & \\
\hline Marketing & $\rightarrow$ & & & & & & \\
\hline Higiene \& Saúde & $\rightarrow$ & & & & & & \\
\hline Alta Direção & $\rightarrow$ & $\begin{array}{l}\text { Planos, políticas } \\
\text { e estratégias }\end{array}$ & $\rightarrow$ & $\begin{array}{l}\text { Formação e } \\
\text { Performance }\end{array}$ & $\rightarrow$ & Eventos culturais & $\rightarrow$ Associados \\
\hline Administração & $\rightarrow$ & $\begin{array}{l}\text { Interesse em ativi- } \\
\text { dades culturais }\end{array}$ & $\rightarrow$ & & $\rightarrow$ & $\begin{array}{l}\text { Cursos de formação } \\
\text { cultural }\end{array}$ & \\
\hline Sociocultural & $\rightarrow$ & $\begin{array}{l}\text { Interesse em ativi- } \\
\text { dades esportivas }\end{array}$ & $\rightarrow$ & & $\rightarrow$ & $\begin{array}{l}\text { Cursos de formação } \\
\text { esportiva }\end{array}$ & \\
\hline Alimentos \& Bebidas & $\rightarrow$ & $\begin{array}{l}\text { Interesse em aperfeiçoa- } \\
\text { mento e performance }\end{array}$ & $\rightarrow$ & & $\rightarrow$ & $\begin{array}{l}\text { Aperfeiçoamento técnico } \\
\text { em modalidades } \\
\text { esportivas }\end{array}$ & \\
\hline Esportes & $\rightarrow$ & & & & $\rightarrow$ & $\begin{array}{l}\text { Desenvolvimento } \\
\text { técnico em modalidades } \\
\text { esportivas }\end{array}$ & \\
\hline Alta Direção & $\rightarrow$ & $\begin{array}{l}\text { Planos, políticas e } \\
\text { estratégias }\end{array}$ & $\rightarrow$ & $\begin{array}{l}\text { Lazer \& En- } \\
\text { tretenimento }\end{array}$ & $\rightarrow$ & Segurança & $\rightarrow$ Associados \\
\hline Sociocultural & $\rightarrow$ & $\begin{array}{l}\text { Necessidades de } \\
\text { convívio familiar }\end{array}$ & $\rightarrow$ & & $\rightarrow$ & Acessos & \\
\hline \multirow[t]{7}{*}{ Esportes } & $\rightarrow$ & $\begin{array}{l}\text { Necessidades de } \\
\text { convívio social }\end{array}$ & $\rightarrow$ & & $\rightarrow$ & $\begin{array}{l}\text { Atividades } \\
\text { disponibilizadas }\end{array}$ & \\
\hline & & $\begin{array}{l}\text { Necessidades relacionadas a } \\
\text { festas e comemorações }\end{array}$ & $\rightarrow$ & & $\rightarrow$ & Eventos sociais & \\
\hline & & Necessidades várias & $\rightarrow$ & & $\rightarrow$ & Buffet para eventos & \\
\hline & & $\begin{array}{l}\text { Necessidades de } \\
\text { convívio esportivo }\end{array}$ & $\rightarrow$ & & $\rightarrow$ & Almoços e jantares & \\
\hline & & & & & $\rightarrow$ & Drinks e Lanches & \\
\hline & & & & & $\rightarrow$ & Serviços em concessão & \\
\hline & & & & & $\rightarrow$ & Recreação esportiva & \\
\hline
\end{tabular}


Tabela 4. Relacionamento entre os Sub-processos, Processos e as Áreas. Fonte: documentação da organização pesquisada.

\begin{tabular}{|c|c|c|}
\hline Sub-processos & Processos & Áreas \\
\hline $\begin{array}{l}\text { Responsabilidade da direção } \\
\text { Monitoramento da política e objetivos da qualidade } \\
\text { Gestão dos recursos } \\
\text { Medição e monitoramento dos processos } \\
\text { Gestão das melhorias contínuas }\end{array}$ & Gestão & $\begin{array}{l}\text { Diretoria executiva } \\
\text { Financeiro } \\
\text { Ombudsman }\end{array}$ \\
\hline $\begin{array}{l}\text { Controle de documentos e registros da qualidade } \\
\text { Gestão dos recursos humanos } \\
\text { Gestão de infra-estrutura e ambiente de trabalho } \\
\text { Aquisição de produtos } \\
\text { Contratação de serviços } \\
\text { Gestão dos dispositivos de medição } \\
\text { Gestão das auditorias da qualidade } \\
\text { Controle das não-conformidades } \\
\text { Aplicação de técnicas estatísticas } \\
\text { Gestão das ações corretivas e preventivas }\end{array}$ & Suporte & $\begin{array}{l}\text { Recursos humanos } \\
\text { Qualidade } \\
\text { Suprimentos } \\
\text { Financeiro } \\
\text { Manutenção } \\
\text { Tecnologia } \\
\text { Comunicação e marketing } \\
\text { Higiene e saúde }\end{array}$ \\
\hline $\begin{array}{l}\text { Realização de produtos e serviços } \\
\text { Aquisição de produtos } \\
\text { Contratação de serviços } \\
\text { Medição, análise e melhoria de produtos e serviços }\end{array}$ & Atendimento & $\begin{array}{l}\text { Administração } \\
\text { Sociocultural } \\
\text { Alimentos e bebidas } \\
\text { Esportes }\end{array}$ \\
\hline $\begin{array}{l}\text { Controle das não-conformidades } \\
\text { Aplicação de técnicas estatísticas }\end{array}$ & Formação \& Performance & $\begin{array}{l}\text { Sociocultural } \\
\text { Esportes }\end{array}$ \\
\hline Gestão das ações corretivas e preventivas & Lazer \& Entretenimento & $\begin{array}{l}\text { Sociocultural } \\
\text { Alimentos e bebidas } \\
\text { Esportes }\end{array}$ \\
\hline
\end{tabular}

As áreas do Clube sabem o que medir orientando-se pelo relacionamento fornecedor/cliente dos processos do organigraph do Clube apresentado na Tabela 4, pois, por meio deste relacionamento, determinam quais processos se encontram envolvidos como fornecedor e/ou cliente, e as respectivas entradas e saídas. Como existe um sistema da qualidade formalizado e implementado, com sub-processos que se relacionam com os processos do organigraph, conforme pode ser visto na Tabela 4, as áreas se orientam por este relacionamento para determinar como medir.

$\mathrm{Na}$ prática, a medição é realizada por departamento, conforme os exemplos da Tabela 5, Tabela 6 e Tabela 7 , com destaques consolidados para a Diretoria Executiva. Nessas medições, os departamentos apresentam suas contribuições para cada um dos processos do organigraph e a situação em que sem encontram em face das metas estabelecidas. Como essas medições são realizadas pelos funcionários dos departamentos, monitoradas pelos supervisores e gerentes, e cobradas pela Diretoria Executiva, além de serem amplamente divulgadas entre os funcionários (afixadas e explicadas pelos supervisores ao pessoal operacional), causa a disseminação dos processos do organigraph por todo Clube. Tal fato leva a constatar que nas áreas bem operacionais, como, por exemplo, nas caldeiras de aquecimento das piscinas ou na brinquedo- teca (setor que cuida de crianças na primeira idade com uso de vários brinquedos), o linguajar dos processos do organigraph é conhecido pelos funcionários destes setores.

A regra simples estabelecida como estratégia para aumentar a participação do associado acaba influenciando, principalmente, as medições dos processos cujo cliente é o associado, ou seja, os processos de Atendimento, Formação \& Performance e Lazer \& Entretenimento. Como para aumentar essa participação cada departamento depende de negociação de uso dos recursos existentes com os demais departamentos, a integração se torna necessária.

Por exemplo, no indicador do Esporte para o processo de Atendimento, conforme a Tabela 5, vê-se que há uma preocupação com o atendimento de propostas. Por meio de análise no local, foi constatado que a maioria destas propostas se referem à adequação de horários de cursos e/ou uso de dependências de maneira que o associado possa aproveitar o período em que se encontra no Clube para realizar mais atividades do que a grade horária e/ou de uso de dependências atual permite, seja no Esporte seja nos outros departamentos. Já no indicador do processo de Formação \& Performance, está sendo medida a quantidade de encaminhamentos de alunos para a área competitiva, de maneira que eles, além de realizarem a atividade formativa, também passem a realizar outras 
Tabela 5. Exemplo de julgamento da estratégia no Esporte. Fonte: documentação da organização pesquisada.

\begin{tabular}{|c|c|c|c|c|}
\hline Processo & Indicador & Meta & Situação & \\
\hline Gestão & $\begin{array}{l}\text { Qualidade nas análises } \\
\text { críticas do SQ. }\end{array}$ & $\begin{array}{l}\text { Obter o máximo de observa- } \\
\text { ções (no requisito } 5 \text { da NBR } \\
\text { ISO 9000:2000) durante } \\
\text { as auditorias da qualidade } \\
\text { (internas e externas). }\end{array}$ & $\begin{array}{l}\text { Zero Observações } \\
\text { Zero Não Conformidades }\end{array}$ & $\Leftrightarrow$ \\
\hline Suporte & $\begin{array}{l}\text { Qualidade no atendimento } \\
\text { (incluindo prazos). }\end{array}$ & $\begin{array}{l}\text { Ter aprovação em no mínimo } \\
80 \% \text { dos atendimentos. }\end{array}$ & $\begin{array}{l}\text { RH /Julho } 2004 \\
\text { Man. } 100 \% \text { Média } 97,5 \% \\
\text { Tec } 95 \% \text {. }\end{array}$ & $\Uparrow$ \\
\hline Atendimento & $\begin{array}{l}\mathrm{N}^{\circ} \text { de propostas viáveis } \\
\text { originadas após a análise } \\
\text { crítica de requisitos } \\
\text { relacionados ao curso. }\end{array}$ & $\begin{array}{l}\text { Atender no mínimo a } 50 \% \\
\text { das propostas. }\end{array}$ & $\begin{array}{l}6 \text { propostas sendo que } 5 \text { poderão ser } \\
\text { implementadas } 83 \% \text {. }\end{array}$ & $\Leftrightarrow$ \\
\hline \multirow[t]{2}{*}{ Formação \& Performance } & $\begin{array}{l}\text { Formação: Aprovação dos } \\
\text { alunos. }\end{array}$ & $\begin{array}{l}\text { Obter no mínimo } 70 \% \text { de } \\
\text { aprovação dos alunos. }\end{array}$ & Avaliação apenas no mês de junho. & \\
\hline & $\begin{array}{l}\text { Performance: Encaminha- } \\
\text { mento de alunos potenciais, } \\
\text { das modalidades competiti- } \\
\text { vas, para a área competitiva. }\end{array}$ & $\begin{array}{l}\text { Encaminhar no mínimo } \\
1 \% \text { dos alunos por período } \\
\text { letivo. }\end{array}$ & $\begin{array}{l}\text { Natação } 22(3,5 \%) \text { - Pólo } 8(14 \%) \\
\text { - Nado } 10(18 \%) .\end{array}$ & $\Leftrightarrow$ \\
\hline \multirow[t]{3}{*}{ Lazer \& Entretenimento } & Número de eventos & $\begin{array}{l}\text { SEFFE: Promover ou partici- } \\
\text { par em no mínimo } 2 \text { eventos } \\
\text { em cada modalidade em cada } \\
\text { semestre. }\end{array}$ & $\begin{array}{l}\text { Apenas EDM/NAT/NAT.KIDS/COM } 2 \\
\text { Eventos no Semestre. }\end{array}$ & $\Downarrow$ \\
\hline & & $\begin{array}{l}\text { SAT: Promover ou participar } \\
\text { de no mínimo } 2 \text { eventos em } \\
\text { cada modalidade em cada } \\
\text { semestre. }\end{array}$ & $\begin{array}{l}\text { Apenas FUT/FSA/GO/HAN/NAT/com } \\
2 \text { eventos no semestre. }\end{array}$ & $\Downarrow$ \\
\hline & Participação nos eventos & $\begin{array}{l}\text { Comparecer, no mínimo, } \\
80 \% \text { dos alunos convocados. }\end{array}$ & $\begin{array}{l}73 \% \text { Presença nos eventos realizados } \\
\text { até junho. }\end{array}$ & $\Downarrow$ \\
\hline
\end{tabular}

Legenda para a situação dos indicadores:

$\Leftrightarrow$ Dentro da expectativa da meta

$\Uparrow$ Facilidade em atingir a meta

$\Downarrow$ Dificuldade em atingir a meta

atividades que vão envolvê-los em mais treinamento e, provavelmente, mais acompanhamento da família durante as competições que ocorrem nesta área. Finalmente, no processo de Lazer \& Entretenimento, há a preocupação de promover eventos esportivos, nos quais haja participação tanto do associado como da sua família.

De maneira semelhante ao que ocorre no Esporte, nota-se que, no Sociocultural (ver Tabela 6), a preocupação com a ocupação de vagas em cursos (processo de Formação \& Performance) e também a freqüência em eventos (processo de Lazer \& Entretenimento) estão alinhadas com a estratégia.

No processo de Lazer \& Entretenimento do setor Alimentos e Bebidas (ver Tabela 7), existe o cuidado de medir freqüência e oferecer serviços (degustação) que tragam o associado ao Clube. No caso particular da degustação, procuram-se oferecer pratos ou bebidas que os concorrentes do Clube também oferecem, mas que ao passarem a fazer parte do menu do Clube terão custo inferior para o associado. Também estabelece-se indicador para medir o aumento do serviço de locações de vídeos oferecido internamente (serviços de concessionários como locação de vídeos, jornaleiro, cabeleireiro, etc., cuidados por este departamento) para que o associado e sua família não tenham que sair para procurar por este serviço fora, abandonando o Clube no período.

Durante a pesquisa deparou-se, por exemplo, com situações de negociação entre os departamentos do Esporte e Alimentos e Bebidas para adequarem horários da pizzaria, de maneira que certos associados que praticam tênis pudessem usar a pizzaria do Alimentos e Bebidas após o término de seus jogos. Na prática, ao terminarem suas atividades, ficou estabelecido que já peçam as pizzas pelo telefone, para que, ao chegarem ao restaurante, já se encontrem prontas para serem servidas.

Apesar do modelo de julgamento apresentado não ser o mais adequado para julgar a importância dos critérios competitivos (coisas importantes que possuem maior relevância para os consumidores (Slack et al., 1997)), nem para avaliá-los ante os concorrentes, no Clube, ele pos- 
Tabela 6. Exemplo de julgamento da estratégia no Sociocultural. Fonte: documentação da organização pesquisada.

\begin{tabular}{|c|c|c|c|c|c|c|c|c|}
\hline \multirow{2}{*}{$\begin{array}{l}\text { Processo } \\
\text { Gestão }\end{array}$} & Indicador & \multirow{2}{*}{\begin{tabular}{|l|c|}
\multicolumn{1}{|c|}{ Meta } \\
Obter o máximo de \\
observações durante as \\
auditorias da qualidade \\
(internas e externas). \\
\end{tabular}} & \multicolumn{6}{|c|}{ Situação } \\
\hline & $\begin{array}{l}\text { Qualidade nas análises } \\
\text { críticas do SQ } \\
\text { (Cap } 5 \text { NBR ISO 9000) }\end{array}$ & & \multicolumn{5}{|c|}{$\begin{array}{l}\text { Não temos observações nem NC na auditoria externa } \\
\text { referente ao capítulo } 5 \text { NBR ISSO } 9000 .\end{array}$} & $\Uparrow$ \\
\hline \multirow[t]{3}{*}{ Suporte } & \multirow{3}{*}{$\begin{array}{l}\text { Qualidade no aten- } \\
\text { dimento (incluindo } \\
\text { prazos). }\end{array}$} & \multirow{3}{*}{$\begin{array}{l}\text { Ter aprovação em no } \\
\text { mínimo } 80 \% \text { dos } \\
\text { atendimentos. }\end{array}$} & \multicolumn{5}{|c|}{ Dados referentes ao perídodo de janeiro a abril de 2005 : } & $\Uparrow$ \\
\hline & & & SSM & Atendidas & Pendentes & \multicolumn{2}{|c|}{$\%$} & \\
\hline & & & 654 & 532 & 122 & \multicolumn{2}{|c|}{81,34} & \\
\hline \multirow[t]{5}{*}{ Atendimento } & \multirow{4}{*}{$\begin{array}{l}\text { Número de registros no } \\
\text { livro de ocorrências. }\end{array}$} & \multirow{4}{*}{$\begin{array}{l}\text { Diminuir em } 10 \% \text { o } \\
\text { número de reclamações } \\
\text { em cursos com relação } \\
\text { ao período anterior. }\end{array}$} & Sociocultural & Sugestões & Reclamações & Elogios & Total & $\Uparrow$ \\
\hline & & & $\begin{array}{l}\text { Jan/Abril } \\
2004\end{array}$ & 23 & 62 & 12 & 97 & \\
\hline & & & $\begin{array}{l}\text { Jan/Abril } \\
2005\end{array}$ & 15 & 14 & 03 & 32 & \\
\hline & & & $\Downarrow$ & $34 \%$ & $77 \%$ & $-75 \%$ & $67 \%$ & \\
\hline & $\begin{array}{l}\text { Tempo para respostas às } \\
\text { ocorrências. }\end{array}$ & No máximo 10 dias. & \multicolumn{5}{|c|}{$\begin{array}{l}\text { Média - } 07 \text { dias } \\
\text { Mediana - } 07 \text { dias }\end{array}$} & $\Uparrow$ \\
\hline $\begin{array}{l}\text { Formação \& } \\
\text { performance }\end{array}$ & $\begin{array}{l}\text { Ocupação das vagas nos } \\
\text { cursos. }\end{array}$ & $\begin{array}{l}\text { No mínimo } 72 \% \text { das va- } \\
\text { gas disponíveis na média } \\
\text { dos cursos. }\end{array}$ & \multicolumn{5}{|c|}{$\begin{array}{l}\text { 76\% } 2692 \text { Vagas disponíveis } \\
2069 \text { Vagas Ocupadas. }\end{array}$} & 介 \\
\hline $\begin{array}{l}\text { Lazer \&entre- } \\
\text { tenimento }\end{array}$ & $\begin{array}{l}\text { Média de Frequiência } \\
\text { dos associados nos } \\
\text { eventos. }\end{array}$ & $\begin{array}{l}\text { "Aumentar em } 10 \% \text { a } \\
\text { média de frequiência } \\
\text { nas Sextas Nobres } \\
\text { comuns, excluindo a } \\
\text { apresentação da Banda } \\
\text { Feeling's". } \\
\end{array}$ & \multicolumn{5}{|c|}{$\begin{array}{l}\text { Jan/Abril 2004: } 98 \text { pessoas } \\
\text { Jan/Abril 2005: } 90 \text { pessoas. }\end{array}$} & $\Downarrow$ \\
\hline
\end{tabular}

Legenda para a situação dos indicadores:

$\Leftrightarrow$ Dentro da expectativa da meta.

$\Uparrow$ Facilidade em atingir a meta.

$\Downarrow$ Dificuldade em atingir a meta.

sui, de maneira indireta, esta função, pois os associados, geralmente, se manifestam tanto fornecendo o grau de importância dos requisitos quanto avaliando o produto que recebem, por comparação com o que pode ser encontrado de maneira semelhante nos prováveis concorrentes do Clube, determinando, assim, um grau de desempenho para o produto ante os concorrentes. Na prática, a maioria dos questionamentos dos associados visa que o Clube seja pelo menos igual, mas freqüentemente melhor, que os seus competidores.

Além disso, os indicadores de satisfação também têm uma parcela de contribuição de julgadores do próprio corpo que gerencia o Clube, os quais participam de entidades que congregam vários clubes e discutem freqüentemente as estratégias dos demais competidores, ou seja, no seu julgamento acabam avaliando também a situação do Clube perante os concorrentes.

Contudo, ressalta-se que o conjunto de indicadores proposto deve ser aprimorado, pois ele prioriza basicamente duas perspectivas, clientes e processos internos. Kaplan e Norton (1992), que introduziram o balanced
scorecard-BSC, sugerem um mapa composto de um scorecard multidimensional, integrando, além das medidas de desempenho clientes e processos internos, as perspectivas financeira e aprendizado e crescimento.

\section{Conclusões}

A escolha do organigraph como forma de representação da estrutura do Clube permitiu evidenciar as competências e alinhá-las aos processos da organização, o que o organograma tradicional não permitia. É importante ressaltar que o processo de reestruturação do Clube emergiu durante o mapeamento dos processos para a implementação de um Sistema de Gestão da Qualidade.

A existência de competências, que levam parte do Clube a trabalhar como uma organização baseada em conhecimento, integra as competências e alinha-as em processos-chave.

O entendimento das competências como os processos cujo cliente final é o associado, e do processo de Gestão envolvendo estas competências com o auxílio do proces- 
Tabela 7. Exemplo de julgamento da estratégia no Alimentos e Bebidas. Fonte: documentação da organização pesquisada.

\begin{tabular}{|c|c|c|c|c|}
\hline Processo & Indicador & Meta & Situação & \\
\hline Gestão & $\begin{array}{l}\text { Qualidade nas análises críticas } \\
\text { do SQ }\end{array}$ & $\begin{array}{l}\text { Obter o máximo de observações (no } \\
\text { requisito } 5 \text { da NBR ISO 9000:2000) } \\
\text { durante as auditorias da qualidade } \\
\text { (internas e externas) }\end{array}$ & $\begin{array}{l}2^{\circ} \text { sem. } 2003 \text { zero obser- } \\
\text { vações e zero não con- } \\
\text { formidades } 2004 \text { ainda } \\
\text { não tivemos auditorias }\end{array}$ & $\Leftrightarrow$ \\
\hline Suporte & $\begin{array}{l}\text { Qualidade no atendimento } \\
\text { (incluindo prazos) }\end{array}$ & $\begin{array}{l}\text { Ter aprovação em no mínimo } 80 \% \\
\text { dos atendimentos. }\end{array}$ & $\begin{array}{l}\text { RH/Julho } 2004 \\
\text { Man.90\% Média } 88 \% \\
\text { Tec } 87 \%\end{array}$ & $\Uparrow$ \\
\hline \multirow[t]{4}{*}{ Atendimento } & $\begin{array}{l}\text { Prazo de atendimento das } \\
\text { solicitações dos pratos }\end{array}$ & $\begin{array}{l}\text { Média de } 20 \text { minutos nos almoço } \\
\text { durante a semana }\end{array}$ & $\begin{array}{l}2003=85 \% \\
2004=100 \%\end{array}$ & $\Uparrow$ \\
\hline & $\begin{array}{l}\text { Conhecimento dos atendentes } \\
\text { quanto aos serviços prestados }\end{array}$ & $\begin{array}{l}\text { Ter pelo menos } 3 / 4 \text { dos atendentes } \\
\text { com resultado igual ou superior a } 80 \% \\
\text { (oitenta por cento) na Lista de } \\
\text { Verificação do Atendimento }\end{array}$ & $\begin{array}{l}2004 \\
\text { Temos } 2 \text { atendentes com } \\
\text { resultado inferior a } 80 \% \\
\text { (oitenta por cento) }\end{array}$ & $\Uparrow$ \\
\hline & $\begin{array}{l}\text { Não conformidades críticas no } \\
\text { atendimento }\end{array}$ & $\begin{array}{l}\text { Não haver mais que uma SAC } \\
\text { corretiva por mês, no atendimento. }\end{array}$ & $\begin{array}{l}2^{\circ} \text { sem. } / 03=3 \\
\text { Jan/abril } 2004=4\end{array}$ & $\Downarrow$ \\
\hline & $\begin{array}{l}\text { Não conformidades críticas } \\
\text { referentes aos concessionários }\end{array}$ & $\begin{array}{l}\text { Não haver mais que uma SAC } \\
\text { corretiva por mês }\end{array}$ & Zero SAC & $\Uparrow$ \\
\hline \multirow[t]{3}{*}{ Lazer \& Entretenimento } & $\begin{array}{l}\text { Quantidade das locações } \\
\text { na Vídeo Locadora }\end{array}$ & $\begin{array}{l}\text { Aumentar pelo menos } 10 \% \text { (dez por } \\
\text { cento) das locações em relação ao ano } \\
\text { anterior }\end{array}$ & $\begin{array}{l}2003=18.963 \\
2004=10.012\end{array}$ & $\Downarrow$ \\
\hline & $\begin{array}{l}\text { Número de frequientadores no } \\
\text { Restaurante e Piano Bar }\end{array}$ & $\begin{array}{l}\text { Aumentar pelo menos } 10 \% \text { (dez por } \\
\text { cento) dos freqüentadores em relação } \\
\text { ao ano anterior }\end{array}$ & $\begin{array}{l}\text { Redução em } 37 \% \\
\text { (trinta e sete por cento) } \\
\text { em relação a } 2003\end{array}$ & $\Downarrow$ \\
\hline & $\begin{array}{l}\text { Quantidade de degustações } \\
\text { oferecidas aos associados }\end{array}$ & $\begin{array}{l}\text { Haver pelo menos uma degustação } \\
\text { semestral }\end{array}$ & 1 & $\Leftrightarrow$ \\
\hline
\end{tabular}

Legenda para a situação dos indicadores:

$\Leftrightarrow$ Dentro da expectativa da meta.

$\Uparrow$ Facilidade em atingir a meta.

$\Downarrow \quad$ Dificuldade em atingir a meta.

so Suporte, só ficou claro quando esta rede foi representada por meio de um organigraph.

A altíssima representatividade do organigraph escolhido permitiu visualizar a estrutura que era percebida, mas não estava explícita. Além disto, foi estabelecida uma regra que, alinhada ao organigraph, levou a facilitar a difusão e aplicabilidade da estratégia.

A absorção entre os diferentes envolvidos da idéia de que eles fazem parte de processos que agrupam atividades as quais, em princípio, parecem tão distintas, mas, na prática, são comuns, e que também podem ser medidas as contribuições individuais, levou-os a estabelecer ações de melhoria conjuntas, as quais passaram a surtir muito mais efeito do que quando propostas por área. Desta maneira, a quantidade de ações propostas por meio destes processos suplantou as ações individuais.

O julgamento da estratégia adotada, por características particulares do associado trazer informações dos concorrentes e solicitar a sua aplicação no Clube, comparando o que é adotado com o que vê nos competidores do Clube, permite que o modelo de análise de indicadores adotado possa ser utilizado indiretamente para medir o posicionamento diante de seus competidores.

Em função da estratégia adotada, os serviços oferecidos passaram a ter uma frequiência muito superior ao que ocorria anteriormente, inclusive nos serviços que não eram habitualmente utilizados pelos associados. Isso acabou exigindo a expansão de capacidade de vários deles, levando, inclusive, alguns associados a questionarem se não estariam vendendo títulos acima do número permitido pelo estatuto, necessitando esclarecer por meio de artigo na revista fornecida periodicamente a todos os associados, que não houve aumento do número de títulos, mas da freqüência e permanência dos associados e seus dependentes no Clube.

Como sugestão para trabalhos futuros, percebe-se a necessidade de se aprofundarem as discussões sobre o sistema de avaliação de desempenho que atualmente prioriza as perspectivas de cliente e processos internos. 


\section{Referências Bibliográficas}

ABNT - ASSOCIAÇÃO BRASILEIRA DE NORMAS TÉCNICAS. NBR ISO 9002: 1994: Sistemas da qualidade - Modelo para garantia da qualidade em produção, instalação e serviços associados. Rio de Janeiro, 1994.

NBR ISO 9001:2000: Sistemas de gestão da qualidade - Requisitos. Rio de Janeiro, 2000.

BLACKLER, F. Knowledge, knowledge work and organizations: an overview and interpretation. Organization Studies, v. 6, n. 16, p. 1021-1046, 1995.

CARVALHO, M. M.; LAURINDO, F. J. B. Estratégias para competitividade. São Paulo: Futura, 2003. 254 p.

COUGHLAN, P.; COGHLAN, D. Action Research for Operation Management. International Journal of Operations \& Production Management, v. 22, n. 2, p. 220-240, 2002.

DRUCKER, P. Post-Capitalist Society. Oxford: Butterworth-Heinemann, 1993.

. The coming of the new organization. Harvard Business Review, p. 45-53, jan./feb. 1988.

EISENHARDT, K. M.; SULL, D. N. Strategy as simple rules. Harvard Business Review, p. 107-116, jan. 2001.

KAPLAN, R. S.; NORTON, D. P. The balanced scorecard - Measures that drive performance. Harvard Business Review, v. 70, n. 1, p. 71-79, 1992.

KINGMAN-BRUNDAGE, J.;GEORGE,W.R.;BOWEN, D. E. "Service logic": achieving service system integration. International Journal of Service Industry Management, UK, v. 6, n. 4, p. 20-39, 1995.
LAWLER, E. E. From job-based to competency-based organizations. Journal of Organizational Behavior, n. 15, p. 3-15, 1994.

LINDGREN, R.; STENMARK, D.; LJUNGBERG, J. Rethinking competence systems for knowledge-based organizations. European Journal of Information Systems, Basingstoke, v. 12, n. 1, p. 18-29, mar. 2003.

MINTZBERG, H.; HEYDEN, L. V. der. Organigraphs: Drawing how companies really work. Harvard Business Review, p. 87-94, sept./oct. 1999.

MINTZBERG, H.; WATERS, J. A. Of strategies, deliberate and emergent. Strategic Management Journal, v. 6, n. 3, p. 257-273, july/sept. 1985.

NONAKA, I. A dynamic theory of organizational knowledge creation. Organization Science, v. 5, n. 1, p. 14-37, 1994.

NONAKA, I.; TAKEUCHI, H. Criação de conhecimento na empresa. Rio de Janeiro: Campus, 1997.

PRAHALAD, C. K.; HAMEL, G. The core competence of the corporation. Harvard Business Review, p. 79-91, may/june 1990.

RABECHINI JR., R.; CARVALHO, M. M. O perfil das competências em equipes de projeto. Revista de Administração de Empresas - RAE Eletrônica, 2003.

SLACK, N.; CHAMBERS, S.; HARLAND, C.; HARRISON, A.; JOHNSTON, R. Administração da Produção. 1. ed. São Paulo: Atlas, 1997. 726 p. 


\title{
STRATEGY AND STRUCTURE: THE QUEST FOR ORGANIZATIONAL ALIGNMENT IN A SOCIAL SPORTS CLUB
}

\begin{abstract}
The academic and practical literature describes organizational typologies that can be classified according to two main categories: job-based and knowledge-based organizations. The organizational structure is most commonly represented or described by the organizational chart. However, this form of representation fails to adequately depict the organization's work dynamics, above all in companies whose key assets are knowledge and experience. To investigate the alignment between strategy and structure, the methodological approach adopted here was that of action research, which was carried out during 2003 and 2004 in a club located in the city of São Paulo. A group of 12 managers, 10 supervisors, 9 coordinators and 5 directors participated in a survey for this research. This article describes how a social, cultural and sports club designed its organizational structure in line with the formation of competencies and their working dynamics in order to operate as a knowledge-based organization. Based on the organigraph concept, the new portrayal of the organization helped the club clarify its emergent strategy for operating in an uncertain and highly competitive market and to implement the organigraph as simple rule to be followed by everyone. A performance measurement model derived from an organigraph is also presented here.
\end{abstract}

Keywords: service strategy, building of competencies, organizational structures, organigraph. 